\title{
Cumulative genetic defects in carcinogen metabolism may increase breast cancer risk (The Netherlands)
}

\author{
Olga L. van der $\mathrm{Hel}^{1}$, H. Bas Bueno-de-Mesquita ${ }^{2}$, Carla H. van Gils ${ }^{1}$, Mark Roest ${ }^{3}$, Barbara Slothouber ${ }^{3}$, \\ Diederick E. Grobbee ${ }^{1} \&$ Petra H. M. Peeters ${ }^{1}$ \\ ${ }^{1}$ Julius Center for Health Sciences and Primary Care, University Medical Center Utrecht, PO Box 85500, 3508 GA, \\ Utrecht, The Netherlands; ${ }^{2}$ Department of Chronic Diseases Epidemiology, National Insitute of Public Health and the \\ Environment, PO Box 1, 3720 BA Bilthoven, The Netherlands; ${ }^{3}$ Division of Clinical Chemistry, University Medical \\ Center Utrecht, PO Box 85500, 3508 GA, Utrecht, The Netherlands; Olga L. van der Hel has as current address: \\ International Agency for Research on Cancer, 69008 Lyon, France
}

Received 29 September 2004; accepted in revised form 26 January 2005

Key words: breast cancer, case cohort, glutathione S-transferase, N-acetyltransferase, smoking.

\begin{abstract}
Variants in the metabolic genes $N A T 1, N A T 2$, GSTM1 or GSTT1, may cause differences in individual detoxifying capacity of possible carcinogens. We examined the cumulative effect of putative at risk genotypes on breast cancer risk and we examined the extent to which these polymorphisms modify the association between smoking and breast cancer. A case cohort study was conducted in the DOM cohort with 676 breast cancer cases and a random sample of 669 individuals. No effect of the NAT1, NAT2 or GSTM1 genotypes on breast cancer risk was observed. However, women with GSTT1 null genotype had a $30 \%$ increased breast cancer risk compared to women with GSTT1 present $(\mathrm{RR}=1.30$ (95\% confidence interval (CI) 1.04-1.64)). Smoking did not influence breast cancer risk nor did genetic variations in NAT1,NAT2 or GSTM1 in combination with smoking. Compared to women who never smoked with GSTT1 present, women with GSTT1 null genotype and who formerly smoked showed an increased breast cancer risk $(\mathrm{RR}=2.55(95 \% \mathrm{CI} 1.10-5.90))$, but current smokers who smoked 20 cigarettes or more per day did not $(\mathrm{RR}=1.06(95 \% \mathrm{CI} 0.51-2.18))$. Increasing numbers of putative at risk genotypes increased breast cancer risk in a dose dependent manner ( $p$ for trend 0.01). The risk was more than doubled in women with all four risk genotypes, $\mathrm{RR}=2.45$ (95\% CI 1.24-4.86), compared to women with zero putative at risk genotypes. In conclusion, the results of this study suggest that presence of three or more putative at risk genotypes increases breast cancer risk.
\end{abstract}

Abbreviations: BMI - body mass index; CI - confidence interval; DOM - diagnostic study on breast cancer; GST glutathione S-transferase; IRR - incidence rate ratio; NAT - N-acetyltransferase

\section{Introduction}

$\mathrm{N}$-acetyltransferase 1 and 2 (NAT1, NAT2), glutathione S-transferase M1 (GSTM1) and T1 (GSTT1) are phase II enzymes, involved in carcinogen metabolism. The genes coding for the NAT enzymes contain polymorphic sites, which cause variable enzymatic activity [1].

* Address correspondence to: Petra H.M. Peeters, Julius Center for Health Sciences and Primary Care; HP: STR 6.1.31, University Medical Center Utrecht, P.O. Box 85060, 3508 BA, Utrecht, The Netherlands. Ph.: +31-30-2509363; Fax: +31-30-2505485; E-mail: p.h.m.peeters@umcutrecht.nl
GSTM1 or GSTT1 null genotype results in a complete lack of enzymatic activity [2]. Individual efficiency to metabolize carcinogens is determined by genetic factors. Polymorphisms in these genes have been associated with an increased risk of several cancers [1].

Several risk factors for breast cancer have been studied, and they may be genetic or environmental or a combination. Among those, smoking is one of the most widely studied environmental risk factor for breast cancer. Results for smoking are inconclusive, but a pooling of 40 studies showed an increased risk for ever smoking of $1.10 \quad(95 \%$ confidence interval (CI) 
1.02-1.18) [3]. Another recent meta-analysis suggests no relation between smoking and breast cancer overall [4]. However, there may be women who are more susceptible for smoking than others because of their genetic composition. Groups of tobacco related carcinogens are converted into metabolites by cytochrome P450 related enzymes. Phase II enzymes are involved in subsequent detoxification of activated metabolites of carcinogens. Both NAT1 and NAT2 are involved in the activation and deactivation of aromatic and heterocyclic amines that can form DNA adducts [5]. Carcinogen-DNA adducts associated with tobacco smoke have been detected in human breast tissue and the mean adduct value was higher for breast cancer cases than for controls [6]. Several studies examined the relation between one genotype and breast cancer, but not all included smoking data or did combine different genotypes [7-9].

The aim of the present study was to investigate both the combined effects of smoking and genetic polymorphisms in relevant metabolic genes (NAT1, NAT2, GSTMI and GSTTI) and the cumulative effect of putative at risk genotypes on breast cancer risk.

\section{Subjects and methods}

\section{Study subjects}

A population-based screening program for early detection of breast cancer was started in 1974, in Utrecht, The Netherlands, the 'DOM' project (Diagnostisch Onderzoek Mammacarcinoom). The project was carried out in four cohorts. Between 1974 and 1979, all women born between 1911 and 1925 (DOM 1 cohort) were invited for screening, in 1981 and 1983 all women born between 1926 and 1931 (DOM 2 cohort), in 1982 until 1985, all women born between 1932 and 1941 (DOM 3 cohort) and in 1985 and 1986, all women born between 1942 and 1945 (DOM 4 cohort). In DOM 1, DOM 3 and DOM 4 participants were asked to bring an overnight urine sample. A total of 25,769 women (DOM 1: 12,242), (DOM 3: 10,229), (DOM 4: 3298) attended the screening and provided a urine sample, that was stored at $-20^{\circ} \mathrm{C}$. Women of the DOM 2 cohort did not provide a urine sample. The participation rate was $70 \%$ [10].

In cooperation with all general practitioners in the region, a breast cancer incidence registry was set up, starting in 1974. From 1987 onwards, the regional cancer registry covered the identification of new cancers, as part of the Netherlands Cancer Registry. Follow-up from 1974 until January 1, 1996 revealed 942 incident breast cancer cases. For the present study 1000 controls were randomly selected from the DOM 1 (800), DOM 3
(160) and DOM 4 (40) cohorts based on the baseline numbers of each DOM cohort with a relatively oversampling of DOM 1 cohort because most cases were expected in this subcohort. During the follow-up 31.1\% was censored due to moving out of the study area or death (DOM 1, 32.7\%; DOM 3, 42.0\%; DOM 4, 12.5\%). The mean follow-up time for the random cohort sample was 15.8 years (standard deviation 5.20). The institutional review board for human studies of the University Medical Center Utrecht approved the study.

\section{DNA isolation}

DNA was isolated from urine by alcohol precipitation as described earlier [11]. Urine samples of the study population were thawed overnight at room temperature, mixed vigorously and $50 \mathrm{ml}$ was used for DNA isolation. In brief, after centrifugation, DNA was isolated from the urine pellet by protein precipitation and DNA was precipitated by alcohol. DNA was finally resuspended in $40 \mu \mathrm{l}(10 \mathrm{mM}$ Tris, $1 \mathrm{mM}$ EDTA, pH 7.6 (TE)).

\section{Genotype}

NAT1 polymorphisms were detected by radioactive dot blot as described previously (11), preceded by PCR using NAT1 specific primers [12]. Briefly, distinction between the $N A T 1 * 3, * 4, * 10$ and $* 11$ alleles was carried out by hybridization at $42{ }^{\circ} \mathrm{C}$ overnight of allele specific oligonucleotides to PCR products spotted on a membrane. The $N A T 1 * 3, * 4, * 10$ and $* 11$ alleles were detected by hybridizing an antisense oligonucleotide for each allele to a separate membrane: $N A T 1^{*} 3\left(5^{\prime} \gamma^{32} \mathrm{P}-\right.$ ATP-agg cca tct tta aaa tac att tat tat ta), NAT1*4 $\left(5^{\prime} \gamma^{32}\right.$ P-ATP-gcc atc ttt aaa aga cat tta tta tta $\left.t t\right)$, $N A T 1^{*} 10\left(5^{\prime} \gamma^{32} \mathrm{P}\right.$-ggc cat ctt taa aat aca ttt ttt att at $)$ and $N A T 1^{*} 11\left(5^{\prime} \gamma^{32} \mathrm{P}\right.$-aaa ata cat tta tta tta tta tta tt gaa aag g). Non-specific binding was removed by $30 \mathrm{~min}$ washing in $2 \times \mathrm{SSC}, 0.1 \%$ SDS at $60{ }^{\circ} \mathrm{C}$ for $N A T 1^{*} 4, N A T^{*} 10$, NAT*11 and at $59{ }^{\circ} \mathrm{C}$ for $N A T 1^{*} 3$. In each experiment three blood samples of known genotype were used as controls for PCR as well as for hybridization. Their sequence was confirmed by DNA sequencing.

For genotype determination four X-ray films were read at the same time. The samples were classified in duplicate as $N A T 1^{*} 3, N A T 1^{*} 4, N A T 1^{*} 10$ or $N A T 1^{*} 11$ homozygote or heterozygote, by two independent observers.

NAT2 polymorphisms at positions $341,590,803$ and 857 were detected by restriction fragment length polymorphism (RFLP) as described earlier [13]. In each experiment three known blood samples were used as 
controls for PCR as well as for RFLP analyses and the sequence was confirmed by DNA sequencing. The alleles were determined according to the known nomenclature [14]. $\mathrm{G}^{191} \mathrm{~A}$ is not determined because it is not seen in Caucasian people [1] and we did not determine the silent mutations at nt 282 and 481.

Presence or absence of the GSTM1 and GSTT1 gene was determined by multiplex PCR as described by Chen et al. [15]. Briefly, segments of GSTM1 and GSTT1 were amplified along with a segment of human $\beta$-globin. The PCR products were analyzed on $2 \%$ agarose gels. A fragment of $215 \mathrm{bp}$ indicated the presence of GSTM1, a fragment of $480 \mathrm{bp}$ indicated the presence of GSTT1 and a fragment of $268 \mathrm{bp}$ indicated the positive internal control $\beta$-globin. All laboratory analyses were performed blinded for case or control status and two observers independently classified all sample results.

\section{Smoking}

Smoking status was assessed at baseline by self-administered questionnaire. In this analysis three smoking classes were considered. Women, who reported smoking in the past, were classified as former smokers. Women who smoked at baseline were classified as current smokers and women who have never smoked were classified as never smokers. For women who smoked currently, information on dose was available and categorized as $<10,10-19, \geqslant 20$ cigarettes/day.

\section{Data analysis}

For ten women the smoking status was not known. DNA was insufficient or the genotyping method failed for NAT1 in 368 participants $(19 \%$ cases and $19 \%$ subcohort), for $N A T 2$ in 260 women (10\% cases and $12 \%$ subcohort), and GSTM1 or GSTT1 genotyping was not possible in 458 women (24\% cases and $22 \%$ subcohort). The percentage successful genotyping is slightly higher for $N A T 1$ and $N A T 2$ than for the GSTM1 and GSTT1. GSTM1 and GSTT1 were determined by a multiplex PCR. An internal control is necessary as control for the PCR success in case of a null genotype, which results in two sets of primers instead of one. This could influence the percentage visible PCR product. Furthermore, we did a pilot study for evaluating such a multiplex PCR and decided that it was more efficient to perform one multiplex PCR with three primers than two multiplex PCR with two primer sets.

For NAT1 the corresponding phenotype is not clear. An initial report on increased activity associated with the $N A T 1^{*} 10$ allele [16] could not be supported in sub- sequent studies [17-20]. However, we maintain the distinction of $N A T 1^{*} 10$ and non $N A T 1^{*} 10$ in our studies. Women with at least one $N A T 1^{*} 10$ allele were classified as rapid acetylators and the rest as slow acetylators. Rapid acetylators served as the reference group in all analyses.

For NAT2 genotype carriers of a $N A T 2 * 4$ or $N A T 2 * 12$ allele were classified as rapid and the rest as slow acetylators [14]. Rapid acetylators were used as reference group. According to some data individuals homozygous for $N A T 2 * 5$ alleles are the slowest acetylators [21], and therefore we also analyzed these individuals compared to the rapid acetylators.

Homozygous GSTM1 null carriers were compared to the reference group of women with at least one GSTMI present, analogous to GSTT1.

Since the 1000 women constitute a random sample of the total cohort $(n=25,769)$, the case cohort analysis was adopted. Multiplication of the person years in the reference group by 25.8 (the inverse of the subcohort non-cases sampling fraction) enabled us to analyze the case cohort as a full cohort, in which person years are unbiased estimates of true person years. Incidence rate ratios (IRR) and corresponding 95\% CIs for breast cancer were estimated using Poisson regression models. Robust 95\% CIs were calculated to account for additional variance introduced by sampling for the cohort [22].

We included women for whom the genotyping was successful, for NAT1 genotyping this resulted in 764 cases and 810 controls, for $N A T 2$ genotyping this were 845 cases and 875 controls, and for GSTM1 and GSTT1 this resulted in 717 cases and 767 controls. For 676 cases and 669 controls all genotyping was successful. We first analyzed the main effects of smoking and of the different genotypes separately. The joint effect of each at risk genotype and smoking was analyzed by combining genotype and smoking status. $p$ Values for tests for trend were calculated.

We also evaluated the effect of a combination of several putative at risk genotypes. According to the number of putative at risk genotypes they possess, women were categorized in five subgroups: none (reference group), women with only one putative at risk genotype (defined as 'non $N A T 1^{*} 10^{\prime}$ ' or ' $N A T 2$ slow genotype' or 'GSTM1 null genotype or 'GSTT1 null genotype'), two, three and four putative at risk genotypes.

Factors considered for confounding were age, DOM cohort $(1,3,4)$, body mass index (BMI) (continuous), nulliparity (yes/no), age at first full term pregnancy (not applicable, $<24,24-27, \geqslant 28$ ), menopause (yes/no), menopausal age (continuous), family history of breast cancer (yes/no). We decided to include possible 
confounders in the model if exclusion changed the estimate by more than $10 \%$. Since this was the case for age and DOM cohort, the final models contain the determinants of interest (smoking, genotype or a combination) and the variables age and DOM cohort. Analyses were performed using SPSS 9.0 and Stata 6.0.

\section{Results}

General characteristics, allele frequencies for $N A T 1$ and $N A T 2$ and genotype frequencies for GSTM1 and

Table 1. Baseline characteristics of the study population

\begin{tabular}{|c|c|c|}
\hline & Cases $N=676$ & $\begin{array}{l}\text { Cohort } \\
\text { sample } N=704\end{array}$ \\
\hline Age & $52.2(6.9)$ & $54.0(6.4)$ \\
\hline Study recruitment (range) & & $40-65$ \\
\hline Height (cm) & $163.8(6.0)$ & $162.5(6.2)$ \\
\hline Weight (kg) & $69.8(11.8)$ & $69.2(10.5)$ \\
\hline $\mathrm{BMI}\left(\mathrm{m}^{2} / \mathrm{kg}\right)$ & $26.0(4.3)$ & $26.2(3.7)$ \\
\hline Age at first full term pregnancy & $26.0(4.1)$ & $26.3(3.7)$ \\
\hline Number of children & $2.8(1.4)$ & $3.1(1.7)$ \\
\hline Nulliparous & $130(19)$ & $134(20)$ \\
\hline \multicolumn{3}{|l|}{ Menopausal status } \\
\hline Premenopausal & $286(42)$ & $213(30)$ \\
\hline Natural postmenopausal & $287(43)$ & $372(53)$ \\
\hline Artificial postmenopausal & $103(15)$ & $119(17)$ \\
\hline Age menopause & $49.7(4.1)$ & $49.6(4.4)$ \\
\hline \multicolumn{3}{|l|}{$\begin{array}{l}\text { Family history of breast cancer } \\
\text { (first relatives) }\end{array}$} \\
\hline Yes & $105(16)$ & $54(8)$ \\
\hline No & $571(84)$ & $650(92)$ \\
\hline \multicolumn{3}{|l|}{ Current use oral contraceptive } \\
\hline Yes & $37(6)$ & $26(4)$ \\
\hline No & $639(94)$ & $678(96)$ \\
\hline \multicolumn{3}{|l|}{ Smoking } \\
\hline Current & $189(28)$ & $193(28)$ \\
\hline \multicolumn{3}{|l|}{ NAT1 alleles } \\
\hline$N A T 1^{*} 3$ & $31(2)$ & 47 (3) \\
\hline$N A T 1^{*} 4$ & $1101(72)$ & $1143(71)$ \\
\hline$N A T 1 * 10$ & $373(24)$ & $399(25)$ \\
\hline$N A T 1^{*} 11$ & $23(2)$ & $31(2)$ \\
\hline \multicolumn{3}{|l|}{ NAT2 alleles } \\
\hline$N A T 2^{*} 4$ & $384(23)$ & $387(22)$ \\
\hline NAT $2 * 5 A$ & $68(4)$ & $87(5)$ \\
\hline$N A T 2 * 5 B$ & $661(39)$ & $700(40)$ \\
\hline$N A T 2 * 5 C$ & $17(1)$ & $41(2)$ \\
\hline$N A T 2^{*} 6 A$ & $467(28)$ & $445(25)$ \\
\hline$N A T 2 * 6 C$ & $7(0)$ & $4(0)$ \\
\hline$N A T 2^{*} 7 B$ & $48(3)$ & $33(2)$ \\
\hline$N A T 2 * 12 A$ & $38(2)$ & $53(3)$ \\
\hline \multicolumn{3}{|l|}{ GSTM1 } \\
\hline Present & $355(50)$ & $396(52)$ \\
\hline Null genotype & $362(50)$ & $371(48)$ \\
\hline \multicolumn{3}{|l|}{ GSTT1 } \\
\hline Present & $443(62)$ & $542(71)$ \\
\hline Null genotype & $274(38)$ & 225 (29) \\
\hline
\end{tabular}

Values are mean (SD) and numbers (percentage).
GSTT1 of the breast cancer cases and the cohort sample are presented in Table 1. No significant difference was observed between the genotyped and non-genotyped persons with respect to these characteristics (data not shown). Breast cancer in first degree relatives was more frequent in cases than in the cohort sample. The distribution of NAT1, NAT2 (and very slow NAT2*5) and GSTMI genotypes was similar among cases and the cohort sample and revealed no increased breast cancer risk. From the cases, 38\% and from the cohort sample $29 \%$ had the GSTT1 null genotype.

Women with GSTT1 null genotype showed a statistically significant, increased breast cancer risk $(\mathrm{RR}=1.30$ (95\% CI 1.04-1.64)), compared to women with GSTT1 present (Table 2). When we analyzed the effects of each genotype separately in the subsample of cases and controls for which we had complete genotype information (676 cases; 669 controls), results were largely the same.

Table 2. NAT1, NAT2, GSTM1, GSTT1 genotypes and breast cancer

\begin{tabular}{llll}
\hline & Cases & Person years & IRR $^{*}$ \\
\hline NAT1 genotype & & & \\
$\quad$ NAT1*10 & 209 & 104,910 & 1.00 \\
$\quad$ Non NAT1*10 & 555 & 222,400 & $1.18(0.94-1.48)$ \\
$\quad$ Total & 764 & & \\
NAT2 genotype & & & \\
$\quad$ Rapid & 364 & 147,863 & 1.00 \\
Slow & 481 & 207,510 & $0.94(0.78-1.14)$ \\
NAT2*5 & 172 & 85,178 & $0.81(0.62-1.05)$ \\
Total & 845 & & \\
GSTM1 & & & \\
$\quad$ Present & 355 & 160,560 & 1.00 \\
$\quad$ Null genotype & 362 & 146,890 & $1.14(0.93-1.42)$ \\
Total & 717 & & \\
GSTT1 & & & \\
$\quad$ Present & 443 & 220,427 & 1.00 \\
$\quad$ Null genotype & 274 & 87,021 & $1.30(1.04-1.64)$ \\
$\quad$ Total & 717 & & \\
\hline
\end{tabular}

* Adjusted for cohort (categorical) and age (continuous).

Table 3. Smoking and breast cancer risk

\begin{tabular}{lrcl}
\hline & Cases & Person years & IRR $^{*}$ \\
\hline Never & 584 & 280,744 & 1.00 \\
Former & 63 & 11,120 & $1.29(0.81-2.03)$ \\
Current & & & \\
$\quad<10 \mathrm{cig} /$ day & 106 & 44,747 & $1.01(0.74-1.36)$ \\
$\quad 10-20 \mathrm{cig} /$ day & 112 & 54,036 & $1.03(0.77-1.38)$ \\
$\quad>20 \mathrm{cig} /$ day & 63 & 17,010 & $1.28(0.83-1.96)$ \\
Total & 928 & & \\
\hline
\end{tabular}

* Adjusted for age (continuous), cohort (categorical). 
Table 4. NAT1, NAT2, GSTM1 genotype, smoking and breast cancer risk

\begin{tabular}{|c|c|c|c|c|}
\hline Genotype & & Cases & $\begin{array}{l}\text { Person } \\
\text { years }\end{array}$ & $\mathrm{IRR}^{*}$ \\
\hline \multicolumn{5}{|l|}{ NAT1 } \\
\hline$N A T 1^{*} 10$ & Never & 133 & 68,485 & 1.00 \\
\hline$N A T 1^{*} 10$ & $\begin{array}{l}\text { Former } \\
\text { Current }\end{array}$ & 13 & 2552 & $1.48(0.58-3.75)$ \\
\hline$N A T 1^{*} 10$ & $<10 \mathrm{cig} /$ day & 23 & 14,963 & $0.73(0.41-1.33)$ \\
\hline$N A T 1 * 10$ & $10-20 \mathrm{cig} /$ day & 25 & 14,976 & $0.94(0.53-1.69)$ \\
\hline$N A T 1^{*} 10$ & $>20 \mathrm{cig} /$ day & 13 & 3,910 & $1.24(0.50-3.06)$ \\
\hline Non $N A T 1 * 10$ & Never & 346 & 155,159 & $1.12(0.85-1.48)$ \\
\hline Non $N A T 1^{*} 10$ & $\begin{array}{l}\text { Former } \\
\text { Current }\end{array}$ & 42 & 6762 & $1.40(0.76-2.56)$ \\
\hline Non $N A T 1^{*} 10$ & $<10 \mathrm{cig} /$ day & 61 & 24,727 & $1.14(0.73-1.77)$ \\
\hline Non $N A T 1 * 10$ & $10-20 \mathrm{cig} /$ day & 61 & 27,746 & $1.10(0.72-1.70)$ \\
\hline Non $N A T 1^{*} 10$ & $>20 \mathrm{cig} /$ day & 36 & 7562 & $1.54(0.83-2.86)$ \\
\hline $\begin{array}{l}\text { Total } \\
\text { NAT2 }\end{array}$ & & 753 & & \\
\hline Rapid & Never & 243 & 102,387 & 1.00 \\
\hline Rapid & $\begin{array}{l}\text { Former } \\
\text { Current }\end{array}$ & 25 & 4430 & $1.25(0.61-2.56)$ \\
\hline Rapid & $<10 \mathrm{cig} /$ day & 33 & 18,250 & $0.66(0.40-1.09)$ \\
\hline Rapid & 10-20 cig/day & 35 & 17,034 & $0.92(0.55-1.52)$ \\
\hline Rapid & $>20 \mathrm{cig} /$ day & 22 & 5690 & $1.31(0.63-2.70)$ \\
\hline Slow & Never & 286 & 143,277 & $0.85(0.66-1.08)$ \\
\hline Slow & $\begin{array}{l}\text { Former } \\
\text { Current }\end{array}$ & 35 & 5583 & $1.24(0.66-2.33)$ \\
\hline Slow & $<10 \mathrm{cig} /$ day & 61 & 20,743 & $1.19(0.78-1.83)$ \\
\hline Slow & $10-20 \mathrm{cig} /$ day & 61 & 28,765 & $0.89(0.60-1.33)$ \\
\hline Slow & $>20 \mathrm{cig} /$ day & 32 & 8740 & $1.08(0.59-1.97)$ \\
\hline $\begin{array}{l}\text { Total } \\
\text { GSTM1 }\end{array}$ & & 833 & & \\
\hline Present & Never & 220 & 108,957 & 1.00 \\
\hline Present & $\begin{array}{l}\text { Former } \\
\text { Current }\end{array}$ & 17 & 4113 & $0.92(0.42-2.01)$ \\
\hline Present & $<10 \mathrm{cig} /$ day & 47 & 19,013 & $0.94(0.43-2.05)$ \\
\hline Present & $10-20 \mathrm{cig} /$ day & 40 & 22,203 & $1.08(0.68-1.72)$ \\
\hline Present & $>20 \mathrm{cig} /$ day & 26 & 6222 & $0.96(0.60-1.54)$ \\
\hline Null genotype & Never & 235 & 103,808 & $1.17(0.90-1.52)$ \\
\hline Null genotype & $\begin{array}{l}\text { Former } \\
\text { Current }\end{array}$ & 34 & 3774 & $1.99(0.99-3.97)$ \\
\hline Null genotype & $<10 \mathrm{cig} /$ day & 31 & 17,919 & $0.87(0.52-1.46)$ \\
\hline Null genotype & $10-20 \mathrm{cig} /$ day & 38 & 16,267 & $1.13(0.68-1.86)$ \\
\hline Null genotype & $>20 \mathrm{cig} /$ day & 19 & 4714 & $1.30(0.60-2.80)$ \\
\hline Total & & 707 & & \\
\hline
\end{tabular}

\footnotetext{
* Adjusted for age (continuous) and cohort (categorical)
}

Compared to women who never smoked, women smoking a high dose of cigarettes (20 or more per day) showed a modest increase in breast cancer risk, although not statistically significant $(\mathrm{RR}=1.28$ (95\% CI $0.83-$ 1.96)) (Table 3). No joint effect of smoking and genotype was observed for NAT1, NAT2 nor GSTM1 genotype (Table 4), nor for smoking in combination with the very slow NAT2*5 (data not shown). Compared to women who never smoked with GSTT1, women without GSTT1 (null genotype) who smoked in
Table 5. GSTT1 genotype, smoking and breast cancer risk

\begin{tabular}{llrrl}
\hline GSTT1 & Cases & $\begin{array}{l}\text { Person } \\
\text { IRR }\end{array}$ \\
& & \multicolumn{2}{l}{${ }^{*}$} \\
& & 289 & 156,652 & 1.00 \\
Present & Never & 26 & 5783 & $1.10(0.57-2.11)$ \\
Present & Former & & & \\
& Current & 52 & 26,015 & $1.03(0.68-1.55)$ \\
Present & $<10 \mathrm{cig} /$ day & 53 & 25,844 & $0.95(0.61-1.46)$ \\
Present & $10-20 \mathrm{cig} /$ day & 43 & 6037 & $1.97(0.99-3.94)$ \\
Present & $>20 \mathrm{cig} /$ day & 25 & 56,115 & $1.43(1.07-1.89)$ \\
Null genotype & Never & 166 & 2105 & $2.55(1.10-5.90)$ \\
Null genotype & Former & 25 & & \\
& Current & & 10,917 & $1.02(0.57-1.82)$ \\
Null genotype & $<10 \mathrm{cig} /$ day & 26 & 12,626 & $1.29(0.76-2.20)$ \\
Null genotype & $10-20 \mathrm{cig} /$ day & 35 & 4,909 & $1.06(0.51-2.18)$ \\
Null genotype & $>20 \mathrm{cig} /$ day & 20 & & \\
Total & & 707 & &
\end{tabular}

* Adjusted for age (continuous) and cohort (categorical).

the past had an increased breast cancer risk, $\mathrm{RR}=2.55$ (95\%CI 1.10-5.90). However, for current smokers no increased risk was observed (Table 5).

When women were classified according to their cumulative number of putative at risk genotypes (non $N A T 1 * 10$ or $N A T 2$ slow genotype, GSTM1 or GSTT1 null genotype), none, one, two, three or four, an increased breast cancer risk with increasing number of putative at risk genotype was apparent. The effect showed a doseresponse relation ( $p$ for trend 0.01 ). The risk was more than doubled in women with all four risk genotypes, $\mathrm{RR}=2.45$ (95\% CI 1.24-4.86) (Table 6). Numbers were too small to determine interaction with smoking.

Results did not change, when analyzing pre- and postmenopausal women separately.

\section{Discussion}

The present study shows that women with increasing number of putative at risk genotypes showed increased breast cancer risk in a dose dependent manner. An effect of GSTT1 null genotype on breast cancer risk was also

Table 6. Breast cancer risk according to cumulative number of putative at risk genotypes (non $N A T 1^{*} 10$ or $N A T 2$ slow genotype or GSTM1 or GSTT1 null genotype)

\begin{tabular}{lrrl}
\hline & Cases & Person years & IRR $^{*}$ \\
\hline No & 26 & 20,250 & 1.00 \\
One & 97 & 46,001 & $1.47(0.84-2.59)$ \\
Two & 292 & 125,756 & $1.58(0.94-2.64)$ \\
Three & 214 & 77,951 & $1.81(1.07-3.06)$ \\
Four & 47 & 11,767 & $2.45(1.24-4.86)$ \\
Total & 676 & & \\
\hline
\end{tabular}

* Adjusted for age (continuous) and cohort (categorical). 
observed, especially for women who have smoked in the past.

A major advantage of case cohort approach over a nested case control study is that it is analyzed as a full cohort and breast cancer incidence rates can be estimated. The incidence rate observed in the first DOM cohort (50 to 70 years in 1975, follow-up to 1996), $\mathrm{IR}=2.64 / 1000$ person years, is of the same order of magnitude as the incidence rate for The Netherlands for 60 to 64 years old women in $1990, \mathrm{IR}=2.52 / 1000$ person years in 1990 [23]. This implies that follow-up of the cohort for breast cancer is virtually complete.

Moreover, in this study smoking data were collected prior to disease occurrence, thus excluding recall bias. Further exclusion of cases occurring in the first year of follow-up did not change the results, indicating that reporting of smoking habits was not biased by presence of latent disease. Genotyping was done blinded to case or control status and misclassification is therefore random and will, if anything, dilute results.

We did not observe increased breast cancer risk for different NAT1, NAT2 and GSTM1 genotypes separately. However, a significant $30 \%$ increased breast cancer risk was observed for GSTT1 null genotype $(\mathrm{RR}=1.30$ (95\% CI 1.04-1.64), especially among former smokers $(\mathrm{RR}=2.55$ (95\% CI 1.10-5.90). An effect of GSTT1 null genotype on breast cancer risk is in agreement with three previous studies [24-26] but such risk was not observed in eight other studies [27-34]. Our observation may be a chance finding, also in view of the absence of an association for current smokers, even for those who smoke more than 20 cigarettes per day. Another explanation might be that former smokers reflect more accurately exposure to carcinogens and the necessary subsequent latency time. Duration may thus be important, but unfortunately this was not asked in the questionnaire. Also, information on exposure to environmental tobacco smoke is lacking.

Our result that $N A T 2$ did not modify smoking effect is in accordance with five other studies [5, 8, 35-37]. In contrast, three studies showed an interaction [38-40], and it was found that DNA-adduct level were significantly elevated in the mammary DNA from women with slow $N A T 2$ acetylator genotype $[41,42]$. We therefore analyzed the very slow NAT2 acetylators $(N A T 2 * 5)$ separately. This revealed no increased breast cancer risk, neither by itself, nor in combination with smoking status. Inconsistencies in results in studies may partly be explained by differences in $N A T 2$ polymorphism determinations, which may lead to misclassification of acetylator type imputed from the genotype [1].

We observed an increased breast cancer risk for women with increasing number of putative at risk genotypes, which was in a dose-response manner. Two other studies reported a positive association of two putative at risk genotypes (GSTM1 and GSTT1 null genotype) and breast cancer [24, 25] and one study reported that genetic polymorphisms of NAT1 and NAT2 modulated breast cancer risk in the presence of GSTM1 and GSTT1 [43]. This may indicate that other enzymes compensate detoxification or activation of carcinogens in case of a single putative at risk genotype.

In conclusion, the results of this study suggest that presence of three or more metabolic putative at risk genotypes increase breast cancer risk in women, but none of these genotypes alone modified the effect of smoking on breast cancer.

\section{Acknowledgements}

We thank Dr N. Kuck Koot for linkage to the cancer registry and we also thank Agnes Burema for assisting in NAT1 genotyping. The study outlined in this manuscript was supported by the Dutch Cancer Society (UU98-1707).

\section{References}

1. Hein DW, Doll MA, Fretland AJ, et al. (2000) Molecular genetics and epidemiology of the NAT1 and NAT2 acetylation polymorphisms. Cancer Epidemiol Biomarkers Prev 9: 29-42.

2. Seidegard J, Vorachek WR, Pero RW, Pearson WR (1988) Hereditary differences in the expression of the human glutathione transferase active on trans-stilbene oxide are due to a gene deletion. Proc Natl Acad Sci USA 85: 7293-7297.

3. Khuder SA, Mutgi AB, Nugent S (2001) Smoking and breast cancer: a meta-analysis. Rev Environ Health 16: 253-261.

4. Collaborative Group on Hormonal Factors in Breast Cancer (2002) Alcohol, tobacco and breast cancer - collaborative reanalysis of individual data from 53 epidemiological studies, including 58,515 women with breast cancer and 95,067 women without the disease. $\mathrm{Br} J$ Cancer 87: 1234-1245.

5. Delfino RJ, Smith C, West JG, et al. (2000) Breast cancer, passive and active cigarette smoking and $\mathrm{N}$-acetyltransferase 2 genotype. Pharmacogenetics 10: 461-469.

6. Perera FP, Estabrook A, Hewer A, et al. (1995) CarcinogenDNA adducts in human breast tissue. Cancer Epidemiol Biomarkers Prev 4: 233-238.

7. Millikan RC (2000) NAT1*10 and NAT1*11 polymorphisms and breast cancer risk. Cancer Epidemiol Biomarkers Prev 9: 217219.

8. Krajinovic M, Ghadirian P, Richer C, et al. (2001) Genetic susceptibility to breast cancer in French-Canadians: role of carcinogen-metabolizing enzymes and gene-environment interactions. Int J Cancer 92: 220-225.

9. Dunning AM, Healey CS, Pharoah PD, Teare MD, Ponder BA, Easton DF (1999) A systematic review of genetic polymorphisms and breast cancer risk. Cancer Epidemiol Biomarkers Prev 8: $843-854$. 
10. de Waard F, Collette HJ, Rombach JJ, Baanders-van Halewijn EA, Honing C (1984) The DOM project for the early detection of breast cancer, Utrecht, The Netherlands. J Chronic Dis 37: 1-44.

11. van der Hel OL, van der Luijt RB, Bueno de Mesquita HB, et al. (2002) Quality and quantity of DNA isolated from frozen urine in population-based research. Anal Biochem 304: 206-211.

12. Bunschoten A, Tiemersma E, Schouls L, Kampman E (2000) Simultaneous determination of polymorphism in N-acetyltransferase 1 and 2 genes by reverse line blot hybridization. Anal Biochem 285: 156-162.

13. van Duijnhoven FJB, van der Hel OL, van der Luijt RB, Bueno de Mesquita HB, van Noord PA, Peeters PHM (2002) Quality of NAT2 genotyping with restriction fragment length polymorphism using DNA isolated from frozen urine. Cancer Epidemiol Biomarkers Prev 11: 771-776.

14. www.louisville.edu/medschool/pharmacology/NAT.html.

15. Chen CL, Liu Q, Relling MV (1996) Simultaneous characterization of glutathione S-transferase M1 and T1 polymorphisms by polymerase chain reaction in American whites and blacks. Pharmacogenetics 6: 187-191.

16. Bell DA, Badawi AF, Lang NP, Ilett KF, Kadlubar FF, Hirvonen A (1995) Polymorphism in the N-acetyltransferase 1 (NAT1) polyadenylation signal: association of NAT1*10 allele with higher $\mathrm{N}$-acetylation activity in bladder and colon tissue. Cancer Res 55: 5226-5229.

17. Bruhn C, Brockmoller J, Cascorbi I, Roots I, Borchert HH (1999) Correlation between genotype and phenotype of the human arylamine N-acetyltransferase type 1 (NAT1). Biochem Pharmacol 58: 1759-1764.

18. Payton MA, Sim E (1998) Genotyping human arylamine $\mathrm{N}$-acetyltransferase type 1 (NAT1): the identification of two novel allelic variants. Biochem Pharmacol 55: 361-366.

19. Butcher NJ, Ilett KF, Minchin RF (1998) Functional polymorphism of the human arylamine $\mathrm{N}$-acetyltransferase type 1 gene caused by C190T and G560A mutations. Pharmacogenetics 8: $67-72$.

20. Smelt VA, Mardon HJ, Sim E (1998) Placental expression of arylamine $\mathrm{N}$-acetyltransferases: evidence for linkage disequilibrium between NAT $1 * 10$ and NAT2*4 alleles of the two human arylamine N-acetyltransferase loci NAT1 and NAT2. Pharmacol Toxicol 83: 149-157.

21. Hein DW, Doll MA, Rustan TD, Ferguson RJ (1995) Metabolic activation of N-hydroxyarylamines and N-hydroxyarylamides by 16 recombinant human NAT2 allozymes: effects of 7 specific NAT2 nucleic acid substitutions. Cancer Res 55: 35313536.

22. Huber P (1967) The behaviour of maximum likelihood estimates under non-standard conditions. In: Proceedings of the Fifth Symposium on Mathematical Statistics and Probability. pp. 221233.

23. Visser O, Coebergh JWW, Schouten LJ (1990) Incidence of Cancer in The Netherlands; second report of The Netherlands Cancer Registry, Utrecht: Hoonte-Holland b.v.

24. Park SK, Yoo KY, Lee SJ, et al. (2000) Alcohol consumption, glutathione S-transferase M1 and T1 genetic polymorphisms and breast cancer risk. Pharmacogenetics 10: 301-309.

25. Zheng T, Holford TR, Zahm SH, et al. (2002) Cigarette smoking glutathione-s-transferase M1 and $\mathrm{t} 1$ genetic polymorphisms, and breast cancer risk (United States). Cancer Causes Control 13: 637-645.

26. Matheson MC, Stevenson T, Akbarzadeh S, Propert DN (2002) GSTT1 null genotype increases risk of premenopausal breast cancer. Cancer Lett 181: 73-79.
27. Helzlsouer KJ, Selmin O, Huang HY, et al. (1998) Association between glutathione S-transferase M1, P1, and T1 genetic polymorphisms and development of breast cancer. $J$ Natl Cancer Inst 90: $512-518$.

28. Garcia-Closas M, Kelsey KT, Hankinson SE, et al. (1999) Glutathione S-transferase $\mathrm{mu}$ and theta polymorphisms and breast cancer susceptibility. J Natl Cancer Inst 91: 1960-1964.

29. Bailey LR, Roodi N, Verrier CS, Yee CJ, Dupont WD, Parl FF (1998) Breast cancer and CYPIA1, GSTM1, and GSTT1 polymorphisms: evidence of a lack of association in Caucasians and African Americans. Cancer Res 58: 65-70.

30. Curran JE, Weinstein SR, Griffiths LR (2000) Polymorphisms of glutathione S-transferase genes (GSTM1, GSTP1 and GSTT1) and breast cancer susceptibility. Cancer Lett 153: 113-120.

31. Millikan R, Pittman G, Tse CK, Savitz DA, Newman B, Bell D (2000) Glutathione S-transferases M1, T1, and P1 and breast cancer. Cancer Epidemiol Biomarkers Prev 9: 567-573.

32. da Fonte de Amorim LM, Rossini A, Mendonca GA, et al. (2002) CYP1A1, GSTM1, and GSTT1 polymorphisms and breast cancer risk in Brazilian women. Cancer Lett 181: 179-186.

33. Gudmundsdottir K, Tryggvadottir L, Eyfjord JE (2001) GSTM1, GSTT1, and GSTP1 genotypes in relation to breast cancer risk and frequency of mutations in the p53 gene. Cancer Epidemiol Biomarkers Prev 10: 1169-1173.

34. Mitrunen K, Jourenkova N, Kataja V, et al. (2001) Glutathione S-transferase M1, M3, P1, and T1 genetic polymorphisms and susceptibility to breast cancer. Cancer Epidemiol Biomarkers Prev 10: 229-236.

35. Morabia A, Bernstein MS, Bouchardy I, Kurtz J, Morris MA (2000) Breast cancer and active and passive smoking: the role of the N-acetyltransferase 2 genotype. Am J Epidemiol 152: 226232.

36. Hunter DJ, Hankinson SE, Hough H, et al. (1997) A prospective study of NAT2 acetylation genotype, cigarette smoking, and risk of breast cancer. Carcinogenesis 18: 2127-2132.

37. Millikan RC, Pittman GS, Newman B, et al. (1998) Cigarette smoking, $\mathrm{N}$-acetyltransferases 1 and 2, and breast cancer risk. Cancer Epidemiol Biomarkers Prev 7: 371-378.

38. Ambrosone CB, Freudenheim JL, Graham S, et al. (1996) Cigarette smoking, $\mathrm{N}$-acetyltransferase 2 genetic polymorphisms, and breast cancer risk. JAMA 276: 1494-1501.

39. Huang CS, Chern HD, Shen CY, Hsu SM, Chang KJ (1999) Association between $\mathrm{N}$-acetyltransferase 2 (NAT2) genetic polymorphism and development of breast cancer in post-menopausal Chinese women in Taiwan, an area of great increase in breast cancer incidence. Int J Cancer 82: 175-179.

40. Chang-Claude J, Kropp S, Jager B, Bartsch H, Risch A (2002) Differential effect of NAT2 on the association between active and passive smoke exposure and breast cancer risk. Cancer Epidemiol Biomarkers Prev 11: 698-704.

41. Pfau W, Stone EM, Brockstedt U, Carmichael PL, Marquardt H, Phillips DH (1998) DNA adducts in human breast tissue: association with N-acetyltransferase-2 (NAT2) and NAT1 genotypes. Cancer Epidemiol Biomarkers Prev 7: 1019-1025.

42. Firozi PF, Bondy ML, Sahin AA, et al. (2002) Aromatic DNA adducts and polymorphisms of CYP1A1, NAT2, and GSTM1 in breast cancer. Carcinogenesis 23: 301-306.

43. Lee KM, Park SK, Doll MA, et al. (2003) N-acetyltransferase (NAT1 and NAT2) and glutathione S-transferase (GSTM1, GSTT1) polymorphisms in breast cancer. Cancer Lett 196: 179-86. 